\title{
A one-dimensional model intercomparison study of thermal regime of a shallow, turbid midlatitude lake
}

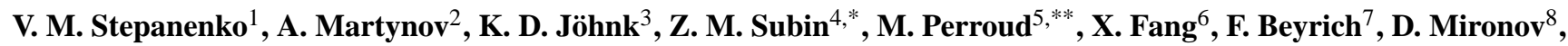 \\ and S. Goyette ${ }^{9}$ \\ ${ }^{1}$ Moscow State University, Research Computing Center, GSP-1, 119234, Leninskie Gory, 1, bld. 4, Moscow, Russia \\ ${ }^{2}$ Centre ESCER, Universite du Quebec a Montreal, 201 Av. du President-Kennedy, Montreal, Canada \\ ${ }^{3}$ CSIRO Land and Water, G.P.O. Box 1666, Canberra, ACT 2601, Australia \\ ${ }^{4}$ Princeton Environmental Institute Guyot Hall, Room 129 Princeton, NJ 08544-1003, USA \\ ${ }^{5}$ University of Michigan, Cooperative Institute for Limnology and Ecosystem Research, School of Natural Resources and \\ Environment, Ann Arbor, MI, USA \\ ${ }^{6}$ Auburn University, Department of Civil Engineering, Auburn, AL 36849-5337, USA \\ ${ }^{7}$ Meteorologisches Observatorium Lindenberg (MOL), Deutscher Wetterdienst (DWD), Lindenberg, Germany \\ ${ }^{8}$ Deutscher Wetterdienst, Forschung und Entwicklung, FE14, Frankfurter Str. 135, 63067 Offenbach am Main, Germany \\ ${ }^{9}$ University of Geneva, Institut des Sciences de l'Environnement, Climatic Change and Climate Impacts, Geneva, Switzerland \\ * formerly at: Earth Sciences Division, Lawrence Berkeley National Lab, Berkeley, CA, USA \\ ** presently at: the Federal Office for the Environment, Papiermühlestrasse 172, 3063 Ittigen, Switzerland
}

Correspondence to: V. M. Stepanenko (stepanen@srcc.msu.ru)

Received: 4 September 2012 - Published in Geosci. Model Dev. Discuss.: 28 November 2012

Revised: 6 June 2013 - Accepted: 7 June 2013 - Published: 30 August 2013

\begin{abstract}
Results of a lake model intercomparison study conducted within the framework of Lake Model Intercomparison Project are presented. The investigated lake was Großer Kossenblatter See (Germany) as a representative of shallow, (2 m mean depth) turbid midlatitude lakes. Meteorological measurements, including turbulent fluxes and water temperature, were carried out by the Lindenberg Meteorological Observatory of the German Meteorological Service (Deutscher Wetterdienst, DWD). Eight lake models of different complexity were run, forced by identical meteorological variables and model parameters unified as far as possible given different formulations of processes. All models generally captured diurnal and seasonal variability of lake surface temperature reasonably well. However, some models were incapable of realistically reproducing temperature stratification in summer. Total heat turbulent fluxes, computed by the surface flux schemes of the compared lake models, deviated on average from those measured by eddy covariance by $17-28 \mathrm{~W} \mathrm{~m}^{-2}$. There are a number of possible reasons for these deviations, and the conclusion is drawn that underes-
\end{abstract}

timation of real fluxes by the eddy covariance technique is the most probable reason. It is supported by the fact that the eddy covariance fluxes do not allow to close the heat balance of the water column, the residual for the whole period considered being $\approx-28 \mathrm{~W} \mathrm{~m}^{-2}$. The effect of heat flux to bottom sediments can become significant for bottom temperatures. It also has profound influence on the surface temperatures in autumn due to convective mixing but not in summer when the lake stratification is stable. Thus, neglecting sediments shifts the summer-autumn temperature difference in models lacking explicit treatment of sediments considerably. As a practical recommendation based on results of the present study, we also infer that in order to realistically represent lakes in numerical weather prediction and climate models, it is advisable to use depth-resolving turbulence models (or equivalent) in favor of models with a completely mixed temperature profile. 


\section{Introduction}

Lakes play an important role in local weather formation and generate specific climate features over the adjacent land. This is caused primarily by the dramatic difference between the lake surface temperature and the temperature of surrounding land that is observed almost always, except when both lake and land are covered by snow. There are also sharp discontinuities at the water bodies' boundaries of other thermodynamic, radiation and aerodynamic surface characteristics, such as roughness height and albedo. This, in turn, causes significant spatial heterogeneity of surface turbulent and radiation fluxes in regions densely occupied by lakes and other water bodies. Land-water contrast of these fluxes has a diurnal cycle that leads to breeze circulation along the shore of large lakes during the ice-free season. In temperate climate zones, the presence of large water bodies modifies surface-air heat exchange on a seasonal timescale. During summers, these water bodies serve as collectors of heat conveyed by solar radiation, while during autumn they release this heat by turbulent fluxes when the water surface is warmer than the air above (Long et al., 2007). Heat released in late autumn and early winter often leads to the development of horizontal convective rolls in the atmospheric boundary layer when cold air outbreak events occur - the classical scenario thoroughly studied in the region of the Laurentian Great Lakes (e.g., Forbes and Meritt, 1984). These examples clearly show the importance of a realistic representation of lakes in numerical weather prediction (NWP) and climate models, such as high-resolution global circulation (or climate) models (GCMs) and regional climate models (RCMs). Water-atmosphere interactions in lake-rich regions have usually been ignored in these models. Lake thermodynamics and hydrodynamics have not yet been routinely applied within land surface schemes. Thus, these land surface schemes were unable to correctly simulate lake surface temperature. During the last decade, however, a number of lake models based on appropriate parameterizations of vertical turbulent heat transport have been introduced in NWP and GCMs/RCMs. The effects of incorporating feedbacks between lakes and atmosphere are presented in a number of papers (Bonan, 1995; Goyette et al., 2000; Hostetler et al., 1993; Mironov et al., 2010; Dutra et al., 2010). The lake models used there have been mainly designed to simulate thermodynamic and radiation interaction between the lake surface and the overlying air. This allows the reproduction of relevant mesoscale circulations and the seasonal cycle of heat exchange at the lakeatmosphere interface, but lacks other interaction processes that are likely to be important on climate timescales (Tranvik et al., 2009). These include the parameterization of biogeochemical interactions and surface fluxes of two principal greenhouse gases - carbon dioxide and methane. However, to the knowledge of the authors, no parameterization of these processes has been yet implemented in any climate model.
Given the number of lake models representing contrasting physical approaches to simulate lake thermodynamics, with their advantages and shortcomings, the LakeMIP (Lake Model Intercomparison Project) initiative was launched after the workshop "Parameterization of Lakes in Numerical Weather Prediction and Climate Modelling" during 18-20 September 2008, in St. Petersburg (Zelenogorsk), Russia. LakeMIP aims at the identification of the key processes that should be represented in different applications of lake models (with special emphasis on climate simulation and weather forecast) regarding the lake physics, lake chemistry, lake hydrology and lake biology, as well as the development and further improvement of their parameterizations (Stepanenko et al., 2010; www.unige.ch/climate/lakemip/index.html).

In the following, the results of one particular study performed in the framework of the LakeMIP project are presented. The analysis deals with the modeling of the thermodynamic regime of a "very shallow lake" (in terms of lake classification used in LakeMIP). The essential peculiarity of very shallow lakes is that they are typically polymictic: they become well-mixed multiple times during the year. This causes two important effects: (i) the magnitude of heat flux at the bottom of such a lake during summer is usually much larger than that in deeper lakes; (ii) relatively large nearbottom velocities cause sediment reloading and hence increased turbidity. Higher turbidity, however, favors shallower temperature stratification due to major part of solar radiation being absorbed in the vicinity of the lake surface. Hence, it is reasonable to expect periods of substantial stratification in these lakes when the wind weakens. Taking this into account, thermal regime simulations for such lakes might differ between models depending on the following features: (i) the presence and the type of parameterization of heat transport in lake sediments; (ii) the parameterization of turbulent mixing in the water column, especially regarding stably stratified turbulence under wind stress; (iii) the formulation of the absorption of solar radiation at the surface and in the water column; and (iv) the parameterizations of surface sensible, latent heat and momentum fluxes. This study considers the effects caused by different treatment of (i-iv) in lake models, whereas physical parameters common to all models (such as albedo) were unified as far as possible. Using spectral dependency of radiation attenuation coefficients may improve the correlation between simulations and in situ temperature measurements for turbid lakes. However, very limited empirical data are available on such a dependency, and hence an "integral" attenuation coefficient has been used in this study. The study does not target at testing physical parameterizations (namely, turbulent mixing and heat exchange at the bottom), rather at quantifying the effect of these parameterizations on lake surface temperature and heat exchange of the lake with the atmosphere.

The emphasis of this study on shallow lakes is supported by the high occurrence of such lakes in mid- and especially high latitudes, including lake-rich regions of Canada, 
Sweden, Finland and Russia (in particular, Karalee and Western Siberia). Compared to deep lakes, thermal inertia of these lakes is weaker. Many regions in which they are abundant (e.g., permafrost regions) are characterized by high soil moisture content and the presence of vast wetland areas. Taking these into account, one might expect that spatial contrasts in surface sensible and latent heat flux associated with the presence of lakes would not be as strong compared to those of dryer climate zones with deeper lakes. Nevertheless, one should consider these owing to the different mechanisms of thermal conductivity in soil and liquid media. Moreover, it is important to reproduce accurately the thermal regime of these lakes because the biogeochemical processes mentioned above, which are common in mid- and high latitudes, are known to be highly sensitive to temperature (e.g., the release of methane is strongly dependent on temperature).

In order to analyze the ability of lake models to realistically simulate the thermal regime of lakes and turbulent fluxes in the air surface layer above water, a complete experimental dataset is necessary. This dataset includes the meteorological forcing (air temperature, humidity, pressure, wind speed and its direction, solar radiation, atmospheric radiation, precipitation), as it determines the upper boundary conditions of lake models, and validation data (vertical temperature profiles, sensible, latent heat fluxes and friction velocity at the lake-atmosphere interface). Note that precipitation data are required only by the LAKE model (see Sect. 2 "Lake models") to compute the mass budget of a lake. All variables listed above are rarely simultaneously measured in situ on a lake over a long time period (several months). In this study, data measured and processed at Großer Kossenblatter See (Germany) (hereafter referred to as Kossenblatter See) by Lindenberg Meteorological Observatory - Richard Aßmann Observatory (DWD, German Meteorological Service) from May to November 2003 have been used. They included the data of the on-lake precipitation sensor inter alia (for details see the Sect. 3 "Observations" and Table 2).

The goal of this study is to assess the capability of different lake models to reproduce the thermal regime of Kossenblatter See and its turbulent heat exchange with the atmosphere during the open-water season. A special emphasis is put on how different treatments of water-sediment heat exchange and vertical turbulent mixing parameterizations affect the correlation of model outputs with experimental data in terms of surface temperature and energy exchange with the atmosphere. Since the sensible and latent heat flux at the water-air interface determine the heat balance in the mixed layer and therefore the vertical water temperature profile, the surface flux schemes are also compared to eddy covariance measurements above this lake.

The paper will first present a short overview of lake models and describe observations that were performed at Kossenblatter See by Lindenberg Meteorological Observatory in 2003 along with the data processing procedures. The results of model intercomparison are then analyzed providing appro- priate physical interpretations and quantitative estimates of the effects of certain model features on model output. Finally, the most important conclusions of the paper are summed up.

\section{Lake models}

Here we provide a short overview of lake models used in the study with special stress on their features relevant to numerical experiments using Kossenblatter See data. A more complete model description is given in the Supplement, and a brief summary of the model features is presented in Table 1. All models used in this study are one-dimensional in the vertical. Note that the bathymetry of Kossenblatter See is rather flat except where it is close to shorelines (Fig. 1), thus making the one-dimensional modeling approach reasonable. These lake models may be classified according to different criteria. From a point of vertical model structure, one may distinguish between bulk or "zero-dimensional" model (also termed hereafter as "completely mixed model"), which assumes homogeneous temperature profile; " 0.5 -dimensional" model (FLake), representing the vertical temperature profile as a mixed layer united with the thermocline with parameterized temperature-depth dependence; and one-dimensional models, explicitly calculating vertical temperature profile on a numerical grid (Hostetler, CLM4-LISSS, MINLAKE96, LAKE, SimStrat and LAKEoneD). These model categories of contrasting numerical complexity are suitable for different applications. For example, a zero-dimensional model may be used in paleoclimate simulations where the effective heat capacity (thermal inertia) of inland water bodies is of major concern and the numerical simplicity is crucial for running climate models on long timescales. On the other hand, one-dimensional models can be applied to many limnological studies where the details of temperature profile become crucial, and these models may potentially predict surface temperatures and heat fluxes more accurately on diurnal and seasonal timescales. The models of this category use either semi-empirical parameterizations of eddy viscosity and thermal conductivity involving stability parameters and wind forcing (Hostetler, CLM4-LISSS and MINLAKE6) or more sophisticated $k-\varepsilon$ turbulence closure (LAKE, SimStrat and LAKEoneD).

Based on the temporal discretization, models are divided into those with daily time steps (MINLAKE96) and diurnalcycle-resolving models (all other models in this study) using time steps down to $1 \mathrm{~min}$.

Lake models are also different in their treatment of interaction with bottom sediments and underlying bedrock. Four models (a completely mixed one, Hostetler, SimStrat and LAKEoneD) assume zero heat flux at the bottom, while the others (FLake, CLM4-LISSS, LAKE and MINLAKE96) compute heat conduction in sediments explicitly. Note that in FLake a self-similarity concept similar to that for the temperature-depth curve in the thermocline is used to 
Table 1. The major features of lake models used in the intercomparison study.

\begin{tabular}{|c|c|c|c|c|c|}
\hline $\begin{array}{l}\text { Lake model, } \\
\text { major publications }\end{array}$ & $\begin{array}{l}\text { Vertical structure/number of layers } \\
\text { in reference run (lake depth } 2 \mathrm{~m} \text { )/ } \\
\text { grid spacing (if equidistant) }\end{array}$ & Time step & $\begin{array}{l}\text { Parameterization of turbulent fluxes } \\
\text { at the lake-atmosphere interface }\end{array}$ & $\begin{array}{l}\text { Turbulent mixing } \\
\text { parameterization }\end{array}$ & $\begin{array}{l}\text { Treatment of heat flux } \\
\text { at the water-bottom } \\
\text { sediment interface }\end{array}$ \\
\hline Completely mixed model & Bulk model/1 & $1 \mathrm{~min}$ & $\begin{array}{l}\text { Monin-Obukhov similarity theory } \\
\text { with Businger interpolation formulae } \\
\text { (Paulson, 1970; } \\
\text { Beljaars and Holtslag, 1991; } \\
\text { Large et al., 1994) }\end{array}$ & $\begin{array}{l}\text { Homogeneous } \\
\text { temperature profile }\end{array}$ & Zero heat flux \\
\hline $\begin{array}{l}\text { FLake, } \\
\text { Mironov (2008), } \\
\text { Mironov et al. (2010), } \\
\text { Kirillin et al. (2011) }\end{array}$ & $\begin{array}{l}\text { Parameterized temperature profile/2 } \\
\text { (top mixed layer and thermocline) }\end{array}$ & $10 \mathrm{~min}$ & $\begin{array}{l}\text { Monin-Obukhov similarity theory } \\
\text { accounting for specific features } \\
\text { of the surface air layer over lakes }\end{array}$ & $\begin{array}{l}\text { Homogeneous temperature } \\
\text { profile in mixed layer } \\
\text { and self-similarity } \\
\text { concept in thermocline }\end{array}$ & $\begin{array}{l}\text { Parameterization of } \\
\text { temperature profile in } \\
\text { bottom sediments (soil) } \\
\text { using self-similarity } \\
\text { hypothesis }\end{array}$ \\
\hline $\begin{array}{l}\text { Hostetler, } \\
\text { Hostetler and Bartlein (1990) }\end{array}$ & Multilayer/20/0.1 m & $10 \mathrm{~min}$ & $\begin{array}{l}\text { A scheme from BATS model } \\
\text { (Dickinson et al., 1993) }\end{array}$ & $\begin{array}{l}\text { Henderson-Sellers } \\
\text { parameterization of } \\
\text { eddy diffusivity, } \\
\text { buoyant convection } \\
\text { (Hostetler and Bartlein, 1990) }\end{array}$ & Zero heat flux \\
\hline $\begin{array}{l}\text { CLM4-LISSS, } \\
\text { Hostetler and Bartlein (1990), } \\
\text { Subin et al. (2011), } \\
\text { Oleson et al. (2010) }\end{array}$ & Multilayer/25 layers & $10 \mathrm{~min}$ & $\begin{array}{l}\text { An extended scheme } \\
\text { from CLM4 model } \\
\text { (Oleson et al., 2010; } \\
\text { Subin et al., 2011) }\end{array}$ & $\begin{array}{l}\text { Henderson-Sellers } \\
\text { parameterization } \\
\text { of eddy diffusivity, } \\
\text { buoyant convection } \\
\text { (Hostetler and Bartlein, 1990) }\end{array}$ & $\begin{array}{l}\text { Heat conductance in bottom } \\
\text { sediments (soil) }\end{array}$ \\
\hline $\begin{array}{l}\text { MINLAKE96, } \\
\text { Fang and Stefan (1996) }\end{array}$ & Multilayer/16 & $24 \mathrm{~h}$ & $\begin{array}{l}\text { Aerodynamic bulk formulae } \\
\text { using a function of wind speed } \\
\text { and momentum or drag coefficient } \\
(\mathrm{Wu}, 1969)\end{array}$ & $\begin{array}{l}\text { Empirical dependence } \\
\text { of eddy diffusivity on } \\
\mathrm{N}^{2}(\text { S.1.1), bulk } \\
\text { mixed-layer model }\end{array}$ & $\begin{array}{l}\text { Heat conductance in bottom } \\
\text { sediments (soil) }\end{array}$ \\
\hline $\begin{array}{l}\text { LAKE, } \\
\text { Stepanenko et al. (2011) }\end{array}$ & Multilayer/20 & $1 \mathrm{~min}$ & $\begin{array}{l}\text { Monin-Obukhov similarity theory } \\
\text { with Businger interpolation } \\
\text { formulae (Paulson, 1970; } \\
\text { Beljaars and Holtslag, 1991; } \\
\text { Large et al., 1994) }\end{array}$ & $\begin{array}{l}k-\varepsilon \text { with Canuto } \\
\text { stability functions }\end{array}$ & $\begin{array}{l}\text { Heat conductance in bottom } \\
\text { sediments (soil) }\end{array}$ \\
\hline $\begin{array}{l}\text { SimStrat, } \\
\text { Goudsmit et al. (2002), } \\
\text { Perroud et al. (2009) }\end{array}$ & Multilayer/40/0.05 m & $10 \mathrm{~min}$ & $\begin{array}{l}\text { Empirical equations } \\
\text { (Livingston and Imboden, 1989; } \\
\text { Kuhn, 1978; } \\
\text { Dingman et al., 1968) }\end{array}$ & $\begin{array}{l}k-\varepsilon \text { with Galperin } \\
\text { stability functions }\end{array}$ & Zero heat flux \\
\hline $\begin{array}{l}\text { LAKEoneD, } \\
\text { Jöhnk and Umlauf (2001), } \\
\text { Jöhnk et al. (2008) }\end{array}$ & Multilayer/20/0.1 m & $3.3 \mathrm{~min}$ & (Rodi, 1993) & $\begin{array}{l}k-\varepsilon \text { with standard } \\
\text { coefficients }\end{array}$ & Zero heat flux \\
\hline
\end{tabular}

describe heat transfer in bottom sediments, while other models solve the thermal diffusion equation (although in different forms) for the sediment layer.

\section{Observations}

Großer Kossenblatter See $\left(14^{\circ} 06^{\prime} 37^{\prime \prime} \mathrm{E}, 52^{\circ} 08^{\prime} 15^{\prime \prime} \mathrm{N}\right.$, $43 \mathrm{~m}$ a.s.l.) is a shallow lake in Germany $(55 \mathrm{~km}$ SE of Berlin) with a mean depth of $2 \mathrm{~m}$ and a maximum depth of $5 \mathrm{~m}$ (Fig. 1). The area of the lake is $168 \mathrm{ha}$. As illustrated in Fig. 1, most of the modest bottom slopes occur in the lake's marginal zone. In 2003 the Lindenberg Meteorological Observatory performed micrometeorological measurements at this lake from 1 May to 10 November 2003 as a contribution to the LITFASS-2003 experiment (Beyrich and Mengelkamp, 2006; Beyrich et al., 2006). The measurement station was located $90 \mathrm{~m}$ from the eastern lake shore, accommodating the sensors listed in Table 2. Open fetch conditions existed for winds from southwest to northeast $\left(200^{\circ} \mathrm{N}\right.$ to $\left.30^{\circ} \mathrm{N}\right)$, with a shoreline distance of between $380 \mathrm{~m}$ and more than $1 \mathrm{~km}$.
The ultrasonic anemometer and the infrared gas analyzer measured the three wind components, temperature and absolute humidity with $20 \mathrm{~Hz}$ sampling rate, while the time interval used to determine the turbulent fluxes of momentum, sensible and latent heat with the eddy covariance method was $10 \mathrm{~min}$. The eddy covariance flux data have undergone the standard transformations and corrections that are generally recommended for this kind of measurements (i.e., double rotation of the coordinate system, buoyancy and cross-wind correction of the sensible heat flux, density correction of the latent heat flux and a simplified correction for spectral losses to which sensor separation between the sonic and the IR hygrometer makes the most important contribution).

All the rest of the meteorological variables were measured at $1 \mathrm{~Hz}$ frequency with $10 \mathrm{~min}$ averaging as well. These data were passed through a data quality control procedure consisting of several steps. For most of the collected data, quicklook plots were created regularly. Obvious outliers identified in these plots were flagged manually. As a second step, an automatic range test was performed for all measured parameters with lower and upper acceptance limits. The third step of the quality control algorithm consisted of a number of 
Table 2. Meteorological variables measured at Kossenblatter See in 2003, 1 May-10 November, by Lindenberg Meteorological Observatory.

\begin{tabular}{lll}
\hline Variable & Sensor & Measurementslevels \\
\hline 1. Water temperature & Pt-100 & $2,10,20,50,100 \mathrm{~cm}$ \\
\hline 2. Radiation fluxes & & \\
\hline 2.1. Shortwave radiation & CM24 & $2.20 \mathrm{~m}$ \\
2.2. Longwave radiation & DDPIR & $2.10 \mathrm{~m}$ \\
2.3. Water surface (skin) temperature & KT 15.82 & $2.10 \mathrm{~m}$ \\
(derived from surface radiation) & & \\
\hline 3. Conventional meteorological variables & \\
\hline 3.1. Air temperature & HMP45D & $2.00 \mathrm{~m}$ \\
3.2. Air humidity & Frankenberger psychrometer & $2.00 \mathrm{~m}$ \\
3.3. Wind speed & F460 & $2.00 \mathrm{~m}$ \\
3.4. Wind direction & USA-1 & $3.85 \mathrm{~m}$ \\
3.5. Pressure & P6520 & $1.5 \mathrm{~m}$ \\
3.6. Precipitation & Pluvio & $1.0 \mathrm{~m}$ \\
\hline 4. Turbulent fluxes & & \\
\hline 4.1. Momentum flux & USA-1 & $3.85 \mathrm{~m}$ \\
4.2. Sensible heat flux & USA-1 & $3.85 \mathrm{~m}$ \\
4.3. Latent heat flux & USA-1 + LI-7500 & $3.85 \mathrm{~m}$ \\
\hline
\end{tabular}

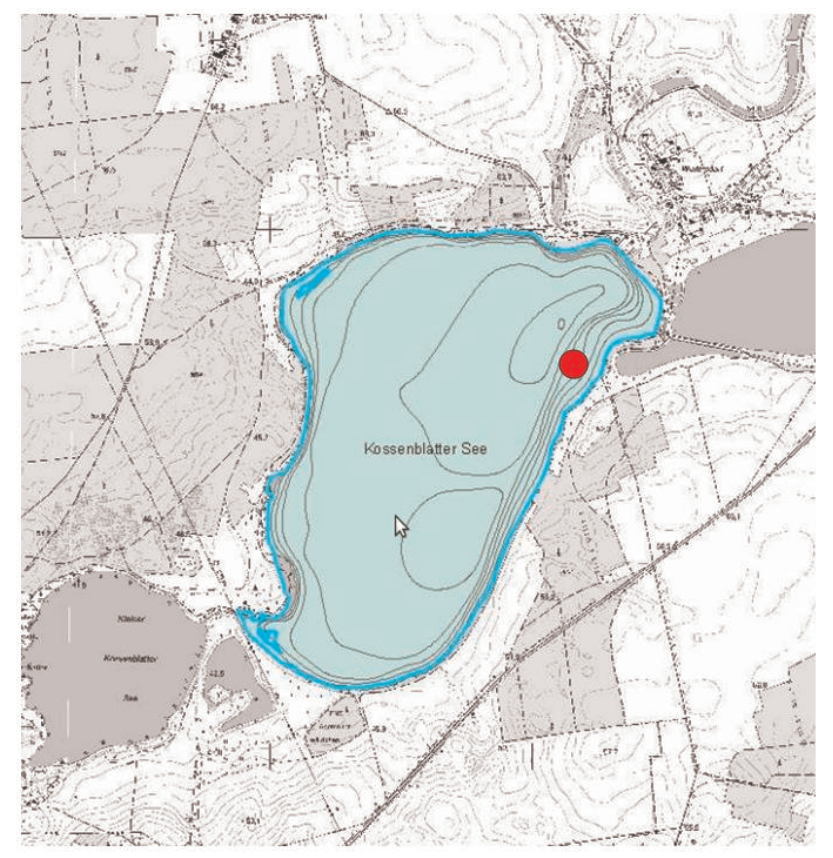

Fig. 1. Kossenblatter See and its neighborhoods. The lake has no major inlet; the only outlet is located in its southwestern section connecting it to Kleiner Kossenblatter See. The depth isopleths are drawn with $0.5 \mathrm{~m}$ increments. The location of measurement mast is denoted by red circle. The map is adopted from the site of Ministry of Environment, Health and Consumer Protection of the Federal State of Brandenburg (http://www.mugv.brandenburg.de). automatic tests, including sensor intercomparison or physically based parameter checks. In addition to these steps, the wind speed measurements in the surface dataset and the turbulent flux values were generally marked by a special flag if distortion of the measurements from the tower and platform constructions or limited fetch conditions due to proximity of the shoreline were suspected.

The original data had a number of gaps, caused by technical problems, with the total length of several days. For the model forcing data, these gaps were filled by linear interpolation (for the slowly varying parameters, if they covered a few 10 min intervals only) or were replaced by data from nearby micrometeorological stations. When the wind sensor at reference level ( $2 \mathrm{~m}$ ) malfunctioned, a wind speed from $0.5 \mathrm{~m}$ level was extrapolated using statistically reliable linear regression between speeds at these two levels. No gap filling was applied to the turbulent flux data.

\section{Experimental setup}

The Kossenblatter See intercomparison experiment aims at quantifying the effects of different physical parameterizations on agreement between lake models and observations in terms of water temperature and energy fluxes at the wateratmosphere interface. In order to ease the interpretation of model output discrepancy, the parameters common to all models were unified as far as possible within the given model formulations and their software implementation. The solar radiation absorption in the water column was represented by an exponential Beer-Lambert formulation in all models 
using the same attenuation coefficient. This coefficient was derived from the empirical relation between Secchi disk depth $z_{\mathrm{SD}}$ and attenuation coefficient $\lambda$ (Poole and Atkins, 1929), $\lambda=k z_{\mathrm{SD}}^{-1}=7.08 \mathrm{~m}^{-1}$, with the constant $k=1.7$, and a measured mean Secchi disk depth $z_{\mathrm{SD}}=0.24 \mathrm{~m}$. The openwater solar radiation albedo value of 0.07 was utilized in the majority of models. Dependency of the shortwave water surface albedo to the solar zenith angle (i.e., if there is direct solar radiation) has been omitted. This is reasonable since no empirical data exist for Kossenblatter See to compute the ratio between direct and diffusive solar radiation (if there is only diffusive radiation, the albedo is nearly constant). Secondly, since albedo increases at high zenith angles when the total solar radiation is low, even large changes of albedo do not increase absorbed radiation significantly. The longwave emissivity of water surface used in the Stefan-Boltzmann law was set to 0.99 in all models.

The initial water temperature profile was unified despite the fact that it is not a critical factor for the results of the Kossenblatter See simulation since the lake is mixed to the bottom multiple times during a year. As to temperature profile in bottom sediments, there was no convention on its initialization.

The sensible, latent and momentum flux parameterizations (hereafter referred to as "surface flux schemes") in the nearwater air layer were not unified. Each model kept the scheme that had been used in it in previous applications. This is mainly due to technical difficulties to embed a single surface scheme in all models. As this might essentially contribute to a discrepancy in model results, an additional surface flux scheme experiment was thus carried out to assess if these schemes produce significantly contrasting heat fluxes. In this experiment the schemes were run using time series of measured meteorological variables and observed water surface temperature. Thus the surface schemes became decoupled from the rest of the lake models, and the deviations of computed turbulent fluxes from measured ones were caused solely by the properties of these schemes and by observation errors.

Lake depth (or water volume) is a crucial parameter for correctly simulating lake thermodynamics and its interaction with atmosphere. Some of the models used in this study explicitly take into account the variation of the horizontal crosssectional area with depth. This requires additional information on lake morphometry, which is not available for the majority of small lakes that have to be parameterized in weather prediction and climate models. Hence it was important to check if lake models are able to reproduce the thermal regime of a lake without detailed information on its bathymetry. For this reason, and in order to exclude morphometry as a factor of discrepancy of models output (i.e., between those including area-depth dependence in model formulation and others), in all model runs the horizontal cross section was set to constant. Three usually used options for specifying a single lake depth can then be considered: average depth
$(2 \mathrm{~m})$, maximal depth $(5 \mathrm{~m})$ and local depth at the point of measurement $(1.2 \mathrm{~m})$. One may expect that specifying local depth may be optimal if a lake body is poorly mixed horizontally, and local vertical processes govern the local surface temperature. Choosing average depth seems preferable when not a local, but an average surface temperature is of primary concern (as it is when a lake model is used within NWP or climate model). It also presents the advantage of preserving the actual lake volume. However, to the knowledge of authors, these qualitative speculations have never been supported by thorough quantitative analysis. Taking all of these into account, all models in this study were run with a single (average) depth of $2 \mathrm{~m}$, but some of them were additionally tested using two other depth options (see Sect. 5.1).

There was not any convention on numerical integration parameters of the models (i.e., the time step, number and spacing of horizontal model layers). The time step in all models allowed resolution of the diurnal cycle, except for MINLAKE96, which was originally designed to simulate daily averaged temperature profiles and other thermodynamic variables.

To clarify the role of heat exchange of the water body with underlying sediments, four models (FLake, Hostetler, CLM4-LISSS and LAKE) were run in separate experiments with the sediment layer either included or neglected.

No numerical experiments included calibration of model parameters or correction of observation data.

\section{Results and discussion}

\subsection{Mixed-layer temperature}

\subsubsection{Mixed-layer temperature in the reference experiment}

The results of model simulations of mixed-layer temperature using observational data have been analyzed. The mixedlayer temperature is defined here as the temperature of the uppermost layer in models explicitly resolving temperature profile on a numerical grid or as the mixed-layer temperature itself for the model that solves a prognostic equation for this variable (i.e., FLake). In observational data, the water temperature at $2 \mathrm{~cm}$ depth was used to characterize the mixed-layer temperature. Hereafter, the "surface temperature" as a synonym of "mixed-layer temperature" is employed. This should not cause confusion with the "skin temperature" (the temperature of a very thin, less than $1 \mathrm{~mm}$, laminar layer at the very top of water column) having temperatures usually less than that below it (Fairall et al., 1996), because none of the models used parameterization of a cool skin. Figure 2 shows the time series of the mixed-layer temperature, calculated by models versus the data of measurements. Two periods in temperature dynamics have been distinguished: the period until the beginning of August, i.e., 

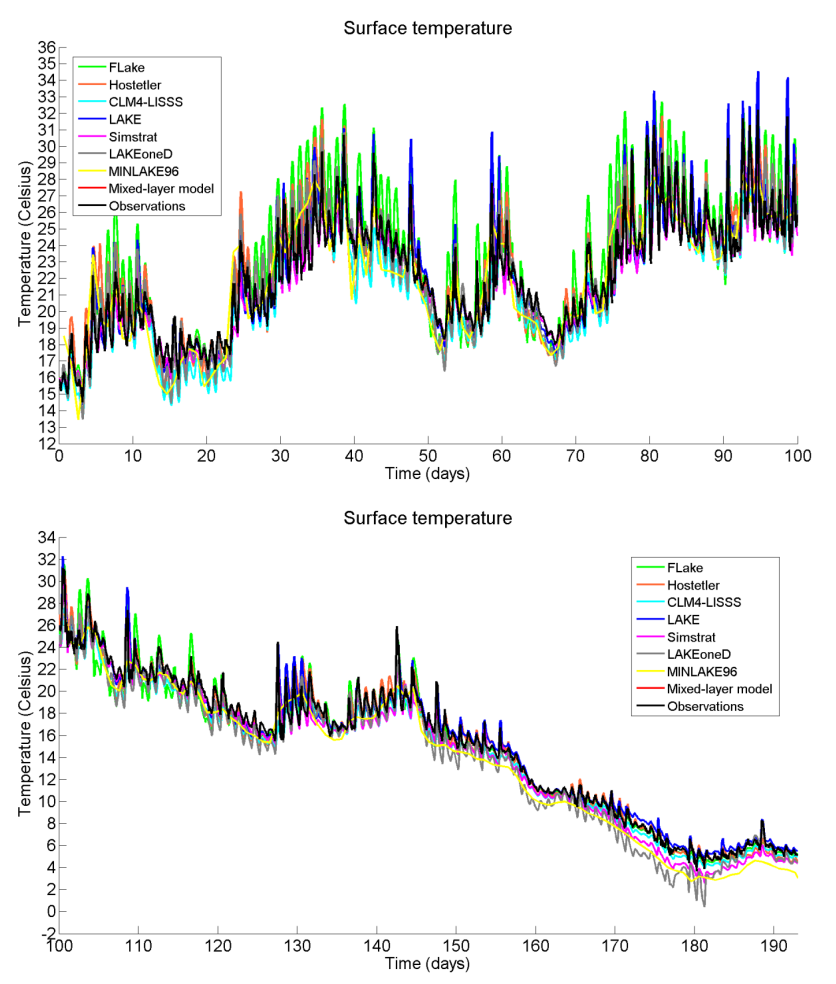

Fig. 2. Time series of mixed-layer temperature of Kossenblatter See by models and from observations. Two panels correspond to two periods - "summer" and "autumn". The time is counted from 00:00 GMT, 1 May 2003.

the first 100 days (1 May-8 August 2003), and the period covering the remaining 90 days ( 9 August -8 November 2003) of simulation. In the rest of the paper, we will also refer to these periods as "summer" and "autumn", respectively. The first period is characterized by high surface temperatures and on average stable stratification in the water column, while during the second period, the surface temperature generally decreases (if omitting diurnal cycle) causing convective mixing in the lake. In the following analysis, these two periods will be considered separately. Figure 2 demonstrates that the majority of models generally capture well the seasonal and diurnal variability of the surface temperature. However, some systematic peculiarities of models can be clearly identified. In the autumn, several models considerably underestimate surface temperature, up to $2-3{ }^{\circ} \mathrm{C}$. During summer, however, the temperature maxima produced by the FLake model often exceed observed values. The temperature simulated by the completely mixed model undergoes a diurnal cycle of much less magnitude than observed.

Figure 3 shows the root mean square errors (RMSEs) of modeled surface temperature and the differences of modeled and observed means (modeled minus observed, hereafter DMs) that quantify the systematic models' deviations from measured data. Note that, hereafter, the RMSE for
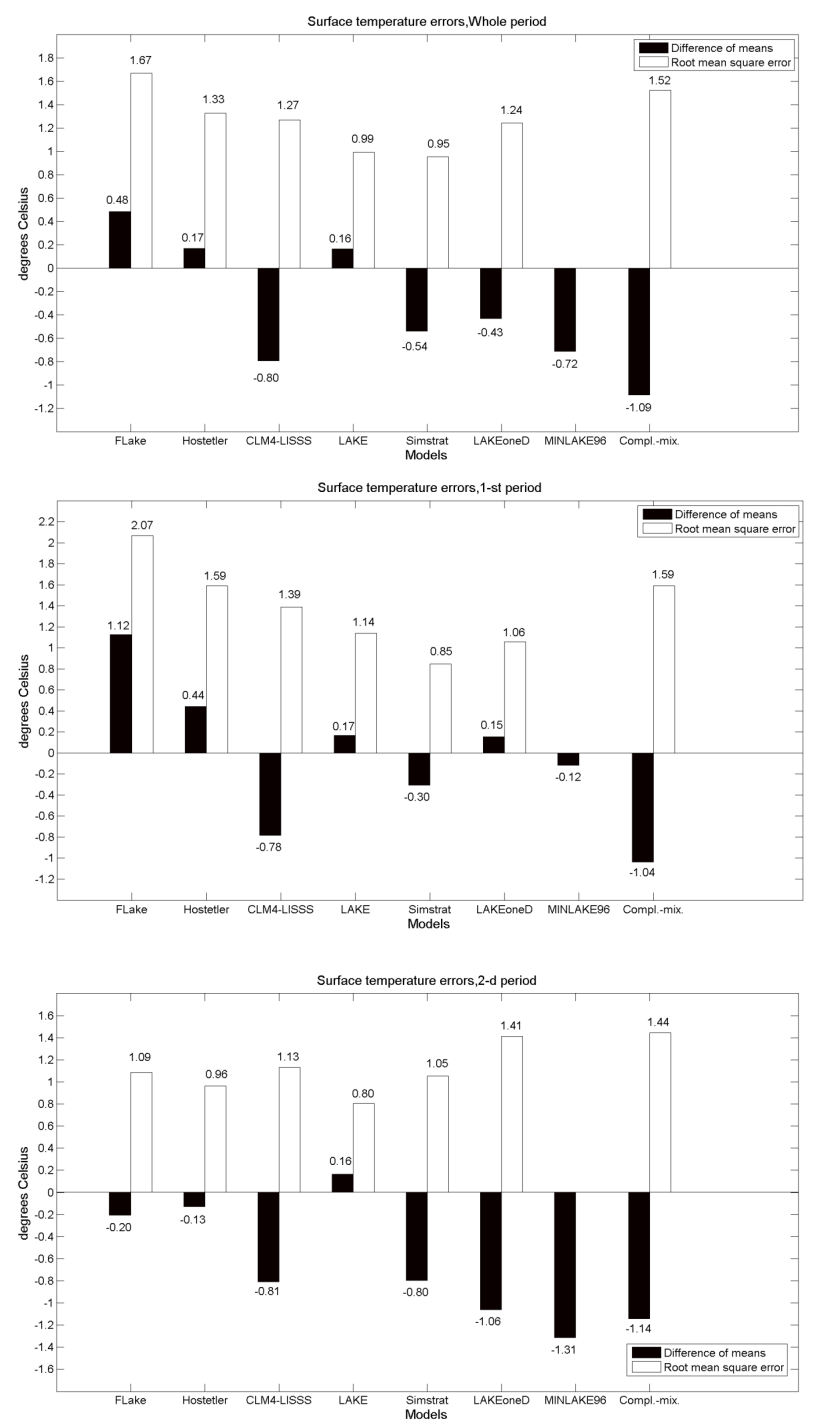

Fig. 3. Differences between modeled and observed means and models' RMSEs of mixed-layer temperature.

MINLAKE96 model is not shown because this model has daily time steps. The correlation between the calculated surface temperature and that measured for all models and their configurations was above 0.97 . For the whole simulation period (Fig. 3, panel 1), the surface temperature RMSE is in a range between 1 and $1.7^{\circ} \mathrm{C}$. Several peculiarities may also be noted for DMs. Firstly, the completely mixed model produced the largest absolute value of DM $\left(-1.09^{\circ} \mathrm{C}\right)$. Then, two lake models, based on the same original Hostetler mixing scheme, namely Hostetler and CLM4-LISSS, have quite different DMs of $0.17^{\circ} \mathrm{C}$ and $-0.8^{\circ} \mathrm{C}$, respectively. This may be attributed to (i) different treatment of solar radiation at the lake surface and below, (ii) different formulation of bottom sediments and (iii) to different surface flux schemes. The influence of these factors will be tested in subsequent sections 


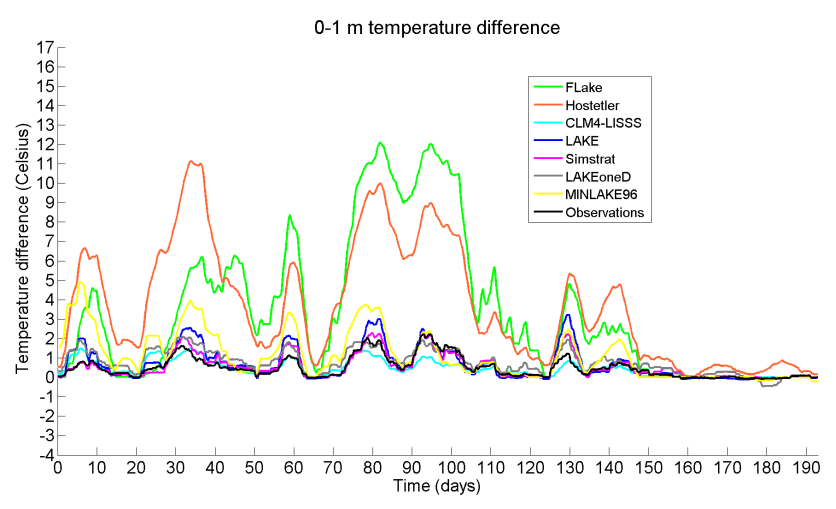

Fig. 4. Time series of $0-1 \mathrm{~m}$ temperature difference by models and from observations (the depth in a point of observations is $1.2 \mathrm{~m}$ ). Both series are smoothed by moving average window equal to 5 days. The time is counted from 00:00 GMT, 1 May 2003.

of the paper. Thirdly, the LAKE model, on one hand, and two other $k-\varepsilon$ models, SimStrat and LAKEoneD, on the other hand, also have contrasting DMs of different signs $\left(0.16^{\circ} \mathrm{C}\right.$, $-0.54{ }^{\circ} \mathrm{C}$ and $-0.43{ }^{\circ} \mathrm{C}$, respectively). Given that turbulent closures for the LAKE, SimStrat and LAKEoneD are similar, this suggests that differences in DMs may be largely due to the treatment of water-sediment exchange and surface flux schemes in these models. The role of the former will be checked later in Sect. 5.1.2 when discussing the effect of explicit bottom sediment heat transport in models on surface temperature.

The values of RMSE and DM for the first period of the experiment are substantially different from those for the whole length of simulations (panel 2 of Fig. 3). Compared with the latter, the DMs of surface temperature by the FLake and Hostetler models are larger and positive $\left(1.12^{\circ} \mathrm{C}\right.$ and $0.44^{\circ} \mathrm{C}$ ), while the temperatures of the three $k-\varepsilon$ models deviate less from that of observations (absolute values of DMs do not exceed $0.3^{\circ} \mathrm{C}$ ). Considering that the FLake contains a bottom sediment parameterization, while two of the $k-\varepsilon$ models do not, this result hints that, in summer when stratification is typically stable, heat exchange with sediments is not strong, and, for simulating surface temperature, it is more important to accurately reproduce the vertical turbulent mixing (which $k-\varepsilon$ models may perform better in this case). The temperature of the completely mixed model is again, on average, lower (by $1.04^{\circ} \mathrm{C}$ ) than the measured mixed-layer temperature, due to the model's inability to reproduce the top radiationally heated mixed layer of the lake (the temperature of this layer in the summer of 2003 often exceeded the temperature of lower layers by several degrees; Fig. 4).

Panel 3 of Fig. 3 shows surface temperature error characteristics in the second period of simulations. The model DMs are quite different from those in summer. Hostetler and FLake models now produced DMs close to zero $\left(-0.20^{\circ} \mathrm{C}\right.$ and $-0.13{ }^{\circ} \mathrm{C}$, respectively), while for CLM4-LISSS and LAKE models, the DMs are almost the same as in the first pe$\operatorname{riod}\left(-0.81{ }^{\circ} \mathrm{C}\right.$ and $0.16^{\circ} \mathrm{C}$, respectively). It should be mentioned that the SimStrat and LAKEoneD models underestimated the mean mixed-layer temperature in autumn significantly $\left(-0.80^{\circ} \mathrm{C}\right.$ and $-1.06^{\circ} \mathrm{C}$, respectively). Given the contrasting (slightly positive) DM of $k-\varepsilon$ model LAKE for this period, this again hints to the lack of heat supply from bottom sediments in SimStrat and LAKEoneD.

\subsubsection{The effect of bottom sediments on the surface temperature}

To check whether bottom heat flux indeed played a minor role in surface temperature variability during the first period, additional runs with three models (CLM4-LISSS, FLake and LAKE) were performed with the routine defining the thermal interaction of the water column with underlying sediments deactivated. In FLake, the sediment layer parameterization can be explicitly switched off, implying a zero heat flux at a lake bottom. In the CLM4-LISSS, the total thickness of the sediment and bedrock column was reduced from $40 \mathrm{~m}$ to $15 \mathrm{~cm}$ (zero was not used to avoid numerical instability), making its total heat capacity negligible; a zero heat flux was imposed at the bottom of this thin sediment layer. In LAKE model, the heat capacity of soil was reduced by a factor of $10^{3}$, making the soil an almost ideally conducting media and leading to an almost zero heat flux at the lake bottom, since at the lower edge of the ground layer this flux is set to zero. As for the completely mixed model, an experiment including bottom heat flux from the LAKE reference run (including sediments) was also performed. Table 3 shows the surface temperature error characteristics, both for reference runs and for those neglecting bottom sediments' effects.

The weakest sensitivity of the mean mixed-layer temperature to neglecting bottom sediments during the first period was shown by FLake $\left(<0.1^{\circ} \mathrm{C}\right)$, which produced a slightly lower temperature than in the corresponding reference run. The other models demonstrated higher summer temperatures when neglecting sediments. This indicates that the mean bottom heat flux in these models was directed from lake to sediments in the reference run, ultimately cooling the surface temperature, which is consistent with watersediment temperature difference typically observed at midlatitude lakes during the warm period. CLM4-LISSS, LAKE and the completely mixed model proved to be slightly more sensitive to the sediment thermal regime than FLake (maximal change in DM $0.23{ }^{\circ} \mathrm{C}$ for CLM4-LISSS model). However, these DM changes are relatively small, and this supports the statement that lake-bottom heat exchange typically is of minor importance for the thermal regime of upper water layers during summer in turbid lakes, even for such a shallow lake as Kossenblatter See.

For three models, excluding interaction with bottom sediments caused larger changes in DM during autumn than 
Table 3. The surface temperature DMs $\left({ }^{\circ} \mathrm{C}\right)$ in reference run and in a run with zero heat flux at the lake bottom.

\begin{tabular}{|c|c|c|c|c|c|c|c|c|c|c|c|c|}
\hline & \multicolumn{3}{|c|}{ FLake } & \multicolumn{3}{|c|}{ CLM4-LISSS } & \multicolumn{3}{|c|}{ LAKE } & \multicolumn{3}{|c|}{ Completely mixed model } \\
\hline & $\begin{array}{l}\text { whole } \\
\text { period }\end{array}$ & period 1 & period 2 & $\begin{array}{l}\text { whole } \\
\text { period }\end{array}$ & period 1 & period 2 & $\begin{array}{l}\text { whole } \\
\text { period }\end{array}$ & period 1 & period 2 & $\begin{array}{l}\text { whole } \\
\text { period }\end{array}$ & period 1 & period 2 \\
\hline $\begin{array}{l}\text { Including sediments/soil } \\
\text { parameterization } \\
\text { (reference run) }\end{array}$ & 0.48 & 1.12 & -0.20 & -0.80 & -0.78 & -0.81 & 0.16 & 0.17 & 0.16 & -1.11 & -1.32 & -0.88 \\
\hline $\begin{array}{l}\text { Excluding sediments } \\
\text { parameterization } \\
\text { (zero heat flux at the bottom) }\end{array}$ & 0.38 & 1.06 & -0.35 & -0.72 & -0.55 & -0.90 & 0.07 & 0.38 & -0.26 & -1.21 & -1.15 & -1.27 \\
\hline
\end{tabular}

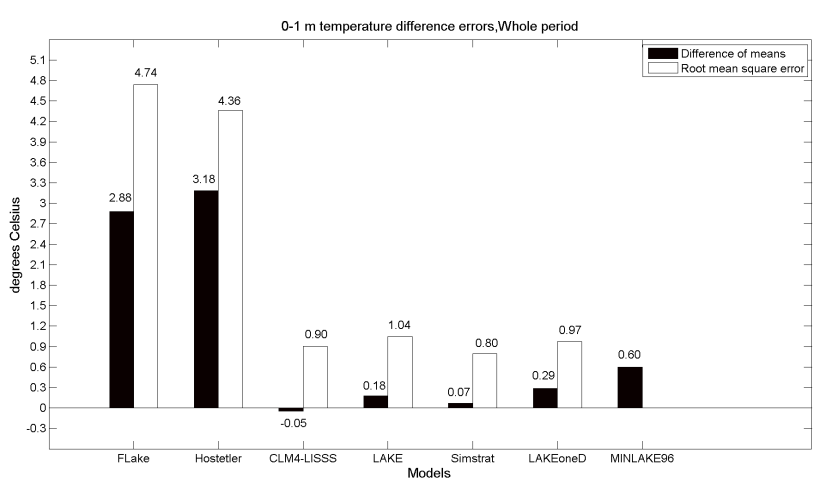

Fig. 5. Difference between modeled and observed means and models' RMSEs of $\delta T_{0-1}$ (temperature difference between 0 and $1 \mathrm{~m}$ depth).

during summer $\left(0.15^{\circ} \mathrm{C}\right.$ versus $0.07^{\circ} \mathrm{C}$ for FLake, $0.42{ }^{\circ} \mathrm{C}$ versus $0.21{ }^{\circ} \mathrm{C}$ for $\mathrm{LAKE}$ and $0.39^{\circ} \mathrm{C}$ versus $0.17^{\circ} \mathrm{C}$ for the completely mixed model). This was an expected result since the vertical heat exchange and hence the bottom heat flux are larger during convective conditions than in stable stratification. The CLM4-LISSS model, on the contrary, had less DM sensitivity in autumn than in summer $\left(0.09^{\circ} \mathrm{C}\right.$ versus $0.23^{\circ} \mathrm{C}$ ). This is caused by high sensitivity of bottom temperature to inclusion of explicit sediment treatment in this model in summer (Fig. 6), much larger than in other models. The reason for this bottom temperature behavior in CLM4LISSS will be discussed in Sect. 5.2. DMs of all models are smaller when utilizing a zero bottom heat flux (i.e., they become more negative or change sign from positive to negative) due to an absence of heat supply from sediments during the autumn cooling of the water column.

In order to quantify the bottom sediment effect on seasonal course of lake model surface temperature, consider now the quantity

$\delta\left(\Delta \bar{T}_{\mathrm{sm}}\right) \equiv\left(\overline{T_{\mathrm{sm} *}^{1}}-\overline{T_{\mathrm{sm} *}^{2}}\right)-\left(\overline{T_{\mathrm{sm}}^{1}}-\overline{T_{\mathrm{sm}}^{2}}\right)$,

where $T_{\mathrm{sm}}$ is the modeled surface temperature, top indices " 1 " and " 2 " denote averages over the first and second period, respectively, and asterisks are used to identify perturbed experiment results. The perturbed experiment is that with heat flux to sediments neglected. The value $\delta\left(\Delta \bar{T}_{\mathrm{sm}}\right)$ indicates how much the "summer minus autumn" surface temperature difference is amplified or decreased in perturbed experiment. Using the definition of DM, one may express this amplification as

$$
\delta\left(\Delta \bar{T}_{\mathrm{sm}}\right)=\left(\mathrm{DM}_{\mathrm{Ts} *}^{1}-\mathrm{DM}_{\mathrm{Ts} *}^{2}\right)-\left(\mathrm{DM}_{\mathrm{Ts}}^{1}-\mathrm{DM}_{\mathrm{Ts}}^{2}\right),
$$

where $\mathrm{DM}_{\mathrm{Ts}}^{i}, i=1,2$ is $\mathrm{DM}$ of surface temperature for the first (summer) or second (autumn) period, respectively. Note also that

$\mathrm{DM}_{\mathrm{Ts}}^{1}-\mathrm{DM}_{\mathrm{Ts}}^{2}=\left(\overline{T_{\mathrm{sm}}^{1}}-\overline{T_{\mathrm{sm}}^{2}}\right)-\left(\overline{T_{\mathrm{so}}^{1}}-\overline{T_{\mathrm{so}}^{2}}\right)$.

Here subscript "o" denotes observed values. This expression shows that $\mathrm{DM}_{\mathrm{Ts}}^{1}-\mathrm{DM}_{\mathrm{Ts}}^{2}$ is the error of seasonal surface temperature difference. Below we will make use of an assumption that lake models with similar turbulent closures should demonstrate similar sensitivity to inclusion of bottom sediments. These models are three $k-\varepsilon$ models, on one hand, Hostetler and CLM4-LISSS models on the other.

Using DMs from Table 3, we obtained that $\delta\left(\Delta \bar{T}_{\mathrm{sm}}\right)=$ $0.63{ }^{\circ} \mathrm{C}>0$ for LAKE model, which is in agreement with the fact that system "water body - soil" has larger thermal inertia than water body alone. Consider also that $\mathrm{DM}_{\mathrm{Ts}}^{1}-\mathrm{DM}_{\mathrm{Ts}}^{2}$ for SimStrat and LAKEoneD models are 0.5 and $1.21^{\circ} \mathrm{C}$ (Fig. 3). Assuming that these two models would have similar sensitivity to including sediments to those of LAKE, we estimated that neglecting sediments may account for at least $50 \%$ of seasonal surface temperature difference error in $k-\varepsilon$ models ( $\sim 100 \%$ of SimStrat and $\sim 50 \%$ for LAKEoneD).

Performing the same analysis with CLM4-LISSS model output, we get an estimate that omitting sediments may account for about $55 \%$ of seasonal surface temperature difference error in Hostetler model $\left(\delta\left(\Delta \bar{T}_{\text {sm }}\right)=0.32^{\circ} \mathrm{C}\right.$ for CLM4-LISSS, $\mathrm{DM}_{\mathrm{Ts}}^{1}-\mathrm{DM}_{\mathrm{Ts}}^{2}=0.57^{\circ} \mathrm{C}$ for Hostetler model).

As a conclusion for this section, the results can be summarized as follows: (i) in summer bottom sediments impose minor influence on modeled surface temperature due to stable stratification (the sensitivity of modeled surface temperature to the activation of sediments routine is $\sim-0.1^{\circ} \mathrm{C}$ ), while (ii) the effect of sediments in autumn is larger in most models 
because of complete convective mixing (surface temperature sensitivity is $0.2-0.4^{\circ} \mathrm{C}$ ); (iii) the error of summer-autumn surface temperature difference can be explained at 50-100\% by the lack of a sediment parameterization (for the models lacking it).

\subsubsection{The effect of depth variation on the surface temperature}

Along with reference model runs, in which the lake depth was set to $2 \mathrm{~m}$ (mean depth of Kossenblatter See), additional runs were performed with models FLake, Hostetler and LAKE using the local depth of the lake at the point of measurements $(1.2 \mathrm{~m})$ and the maximal lake depth $(5 \mathrm{~m})$ as input parameters (assuming no change on the lake surface area). The effect of using these depth values on model surface temperature DMs is displayed in Table 4. In the first period for the FLake and Hostetler models, the DM increases with increasing depth (from $1.01{ }^{\circ} \mathrm{C}$ to $1.30^{\circ} \mathrm{C}$ and from 0.36 to $0.50{ }^{\circ} \mathrm{C}$ respectively, when changing depth from $1.2 \mathrm{~m}$ to $5 \mathrm{~m}$ ). However, the dependency is opposite for LAKE (DM decreases from $0.28^{\circ} \mathrm{C}$ to $-0.19^{\circ} \mathrm{C}$ with the same depth change). This can be attributed to overestimation of stratification strength (the vertical temperature gradient directed upwards) in FLake and Hostetler (see Sect. 5.2), thus reducing heat exchange between top layers and near-bottom layers. In these models, it appears that when the lake depth increases, this decoupling between upper and lower layers becomes stronger, leading to higher surface temperatures. The opposite dependence of DM on depth obtained in the LAKE model is likely to be caused by its more intense vertical mixing, compared to the FLake and Hostetler in summer: increasing depth makes the modeled lake surface more "resistant" to heating by solar radiation due to persisting mixing of near-surface layers with deeper cold layers, cooling the lake surface. During the autumn, the DM response to increasing depth of the three models is qualitatively similar. During this period, when the heat loss to the atmosphere cools the surface water, the convective mixing brings a lake to an almost homogeneous vertical thermal structure even in lakes of considerable depth; therefore, increasing depth leads to slower cooling, warmer lake and higher surface temperature DM.

The data of Table 4 do not allow a conclusion on whether local or mean depth is optimal in the studied case for reproducing lake surface temperature. The DMs and RMSEs of mixed-layer temperature in runs with $1.2 \mathrm{~m}$ and $2 \mathrm{~m}$ depth deviate by $\sim 0.1{ }^{\circ} \mathrm{C}$, which is in the range of the resolution of temperature sensors. These results also suggest that the "optimal depth" delivering the most realistic surface temperature is model-dependent. However, due to the low sensitivity of surface temperature to variations in lake depth around the mean depth (where the optimal depth is likely to fall in all models), an optimal depth delivered by one lake model will not cause significant errors in surface temperature in other models. This argues that the global lake depth datasets de-

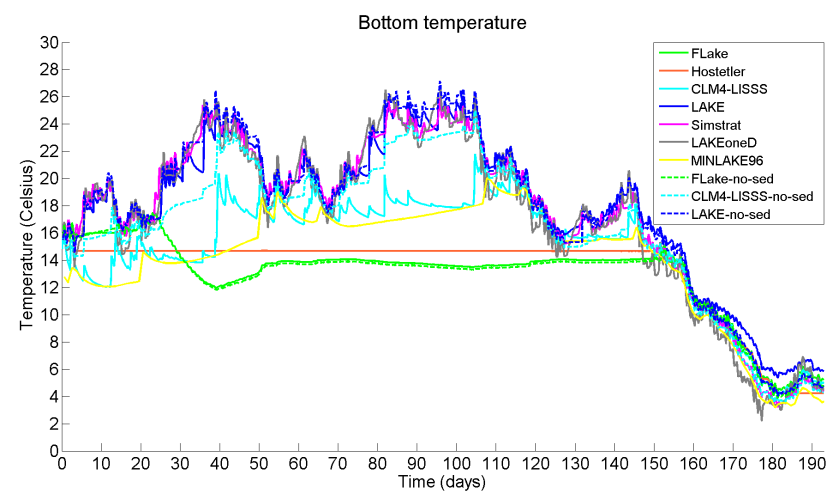

Fig. 6. Time series of bottom temperature of Kossenblatter See produced by models. The time is counted from 00:00GMT, 1 May 2003.

rived by minimizing the surface temperature error of a particular model (e.g., Balsamo et al., 2010) can be used in NWP and climate models utilizing other lake parameterizations (at least as long as relatively shallow lakes are concerned).

\subsection{Stratification and bottom temperature}

In this section, the ability of models to reproduce the lake stratification will be briefly considered. Lake stratification is important in limnological applications, in modeling biogeochemical processes that may constitute feedback with climate change, and indirectly affects heat fluxes to the atmosphere. Time series of bottom temperatures will be analyzed as well. As there is no observational data on the bottom temperature of Kossenblatter See gathered in the framework of the LITFASS-2003 experiment, calculated time series will be examined only qualitatively.

As a measure of temperature stratification, we use the difference between surface temperature and temperature at $1 \mathrm{~m}$ depth (the location of deepest temperature sensor), $\delta T_{0-1}$. Following the methodology used in the previous section, the DMs and RMSEs of $\delta T_{0-1}$ between modeled and measured values were calculated (Fig. 5). These model errors can be visually identified from time series of $\delta T_{0-1}$ drawn at Fig. 4.

The depth of Kossenblatter See at the measurement site $(1.2 \mathrm{~m})$ is close to that of the the lower temperature sensor $(1 \mathrm{~m})$, so that the bottom heat flux may significantly influence the values of $\delta T_{0-1}$. In order to verify this, a numerical experiment with a $1.2 \mathrm{~m}$ depth (Table 5) was compared to the $2 \mathrm{~m}$ depth experiment for two models including sediment parameterization (FLake and LAKE). The stratification parameter $\delta T_{0-1}$, defined as the $0-1 \mathrm{~m}$ temperature difference, differed in $1.2 \mathrm{~m}$ and $2 \mathrm{~m}$ experiments, in terms of both DM and RMSE, by $\sim 0.1{ }^{\circ} \mathrm{C}$. As it is comparable with the measurements error, we conclude that sediments do not affect substantially the stratification in these models.

As seen from Fig. 5, FLake and Hostetler models overestimated $\delta T_{0-1}$ (by $2.88^{\circ} \mathrm{C}$ and $3.18^{\circ} \mathrm{C}$, respectively), 
Table 4. The surface temperature errors $\left({ }^{\circ} \mathrm{C}\right)$ in model experiments when using different lake depths $(h)$.

\begin{tabular}{|c|c|c|c|c|c|c|c|c|c|c|}
\hline & & \multicolumn{3}{|c|}{ FLake } & \multicolumn{3}{|c|}{ Hostetler } & \multicolumn{3}{|c|}{ LAKE } \\
\hline & & $\begin{array}{l}\text { whole } \\
\text { period }\end{array}$ & period 1 & $\begin{array}{r}2 \\
\text { period } 2\end{array}$ & $\begin{array}{l}\text { whole } \\
\text { period }\end{array}$ & period 1 & period 2 & $\begin{array}{l}\text { whole } \\
\text { period }\end{array}$ & period 1 & period 2 \\
\hline \multirow{2}{*}{$\begin{array}{l}h=1.2 \mathrm{~m} \text { (local depth } \\
\text { in point of measurements) }\end{array}$} & DM & 0.39 & 1.01 & -0.28 & -0.06 & 0.36 & -0.51 & 0.08 & 0.28 & -0.14 \\
\hline & RMSE & 1.59 & 1.96 & 1.07 & 1.42 & 1.62 & 1.16 & 1.03 & 1.20 & 0.83 \\
\hline \multirow{2}{*}{$\begin{array}{l}h=2 \mathrm{~m} \text { (mean depth, } \\
\text { reference run) }\end{array}$} & $\mathrm{DM}$ & 0.48 & 1.13 & -0.20 & 0.17 & 0.44 & -0.13 & 0.16 & 0.17 & 0.16 \\
\hline & RMSE & 1.67 & 2.07 & 1.09 & 1.33 & 1.59 & 0.96 & 0.99 & 1.14 & 0.80 \\
\hline \multirow{2}{*}{$\begin{array}{l}H=5 \mathrm{~m} \text { (maximal depth } \\
\text { of Kossenblatter See) }\end{array}$} & DM & 0.88 & 1.30 & 0.42 & 0.60 & 0.50 & 0.72 & 0.45 & -0.19 & 1.13 \\
\hline & RMSE & 1.69 & 1.94 & 1.36 & 1.51 & 1.60 & 1.42 & 1.47 & 1.30 & 1.63 \\
\hline
\end{tabular}

which means that, on average, they produced larger vertical temperature gradients (stratification) than observed. During October and beginning of November, FLake and Hostetler models, along with other models, reproduced well the almost homogeneous thermal structure (weak stratification) developed due to convection (Fig. 4). Therefore, the overestimation of $\delta T_{0-1}$ is largely due to the periods of very strong stratification occurring in summer and beginning of autumn (Fig. 4). It is consistent with positive DMs of surface temperature produced by these models during the first period (Fig. 3): weak mixing leads to overheating of the top mixed layer and with a low (compared to results from other models) bottom temperature (Fig. 6). Note, however, that CLM4LISSS (which is a Hostetler-based model inheriting original Hostetler turbulent mixing scheme) successfully reproduced the stratification (Fig. 5). It cannot be attributed to the presence of soil heat conductance in CLM4-LISSS because bottom heat flux should on average increase the stratification in the water column during summertime. We explain the difference in stratification between CLM4-LISSS and Hostetler by the modification of radiation scheme in the former. Namely, the visible part of shortwave radiation is absorbed in CLM4LISSS according to Beer-Lambert law below $0.6 \mathrm{~m}$ depth, not immediately beneath the surface as it is in other models. For such a turbid lake as Kossenblatter See, it means that strong heat source is located at $0.6 \mathrm{~m}$ depth, not at the surface, as expected. It causes a mid-depth temperature rise and the cooling of surface temperatures, leading to weaker stratification. The systematic underestimation of the surface temperature by CLM4-LISSS during the whole simulation period (Fig. 3) supports this conclusion.

The bottom temperature in FLake and Hostetler is not expected to rise substantially in summer due to very low turbulent heat flux from above in these models, taking into account that solar radiation does not penetrate to the bottom due to high water turbidity. Figure 6 also shows that three $k-\varepsilon$ models produce close bottom temperatures in the summer despite two of the three models neglecting bottom heat flux. This again supports the statement that, in the summer, heat exchange with bottom sediments does not play an important role in the thermal regime of the Kossenblatter See. The bot- tom temperature of CLM4-LISSS model during summer is significantly lower (up to $10^{\circ} \mathrm{C}$ ) than that of $k-\varepsilon$ models (i.e., developing a very strong stratification close to bottom in this shallow lake from the onset of the experiment). Unlike other models, the bottom temperature of CLM4-LISSS and MINLAKE96 decreases in the first 15 days of experiment (first half of May), suggesting that initial soil temperature profiles in these models were subject to low temperatures causing cooling of the bottom before heat flux from above became high enough. Given the deep sediment/rock layer considered in CLM4-LISSS model $(40 \mathrm{~m})$, the initial cool temperature profile in soil would naturally impose a cooling effect on bottom temperature throughout an integration period. One may also notice that the CLM4-LISSS bottom temperature series contain abrupt "jumps" of $2-3^{\circ} \mathrm{C}$, followed by gradual cooling that can be attributed to mixing events in the water column. Similar events can be seen at the LAKE model bottom temperature curve.

Figure 6 demonstrates also the results from three models (FLake, CLM4-LISSS and LAKE) that were launched with neglected bottom sediments. The bottom temperature response to neglecting sediments is much stronger for the CLM4-LISSS model than it is for the FLake and LAKE. We do not speculate about the reasons for that since the scope of the study does not include the details of heat transfer in bottom sediments. Note, however, that the rise of bottom temperature by $2-6^{\circ} \mathrm{C}$ in the CLM4-LISSS during summer when neglecting sediments leads to a mean surface temperature change in this model of only $0.23^{\circ} \mathrm{C}$, arguing again for a minor contribution of lake-bottom heat interaction into mixed-layer thermal regime during the summer period in the Kossenblatter See.

\subsection{Turbulent heat fluxes in water-air interface and one-dimensional heat balance of Kossenblatter See}

In this section the ability of lake models to simulate sensible and latent heat fluxes to the atmosphere is examined. The convention that the heat fluxes are positive when directed upward from the lake to the atmosphere is followed. Figure 7 shows DMs and RMSEs of calculated values for the whole period of simulation. All measured flux values, disregarding 
Table 5. The $0-1 \mathrm{~m}$ temperature difference errors $\left({ }^{\circ} \mathrm{C}\right)$ in model experiments when using different lake depths $(h)$. The mean observed $\delta T_{0-1}$ is $0.50{ }^{\circ} \mathrm{C}$ for the whole period, $0.72{ }^{\circ} \mathrm{C}$ and $0.26^{\circ} \mathrm{C}$ for 1 st and 2 nd periods, respectively.

\begin{tabular}{|c|c|c|c|c|c|c|c|c|c|c|}
\hline & & \multicolumn{3}{|c|}{ FLake } & \multicolumn{3}{|c|}{ Hostetler } & \multicolumn{3}{|c|}{ LAKE } \\
\hline & & $\begin{array}{l}\text { whole } \\
\text { period }\end{array}$ & period 1 & $\begin{array}{r}2 \\
\text { period } 2\end{array}$ & $\begin{array}{l}\text { whole } \\
\text { period }\end{array}$ & period 1 & period 2 & $\begin{array}{l}\text { whole } \\
\text { period }\end{array}$ & period 1 & period 2 \\
\hline \multirow{2}{*}{$\begin{array}{l}h=1.2 \mathrm{~m} \text { (local depth in } \\
\text { point of measurements) }\end{array}$} & $\mathrm{DM}$ & 2.90 & 4.48 & 1.21 & 4.30 & 6.22 & 2.24 & 0.09 & 0.15 & 0.03 \\
\hline & RMSE & 4.55 & 5.85 & 2.48 & 5.68 & 7.17 & 3.46 & 1.00 & 1.20 & 0.71 \\
\hline \multirow{2}{*}{$\begin{array}{l}h=2 \mathrm{~m} \text { (mean depth, } \\
\text { reference run) }\end{array}$} & $\mathrm{DM}$ & 2.88 & 4.29 & 1.36 & 3.18 & 4.69 & 1.56 & 0.18 & 0.26 & 0.09 \\
\hline & RMSE & 4.74 & 5.92 & 2.98 & 4.36 & 5.58 & 2.43 & 1.06 & 1.25 & 0.81 \\
\hline \multirow{2}{*}{$\begin{array}{l}H=5 \mathrm{~m} \text { (maximal depth } \\
\text { of Kossenblatter See) }\end{array}$} & $\mathrm{DM}$ & 0.42 & 0.59 & 0.24 & 2.84 & 4.35 & 1.22 & 0.21 & 0.38 & 0.03 \\
\hline & RMSE & 1.21 & 1.44 & 0.88 & 4.03 & 5.24 & 2.05 & 1.09 & 1.37 & 0.69 \\
\hline
\end{tabular}
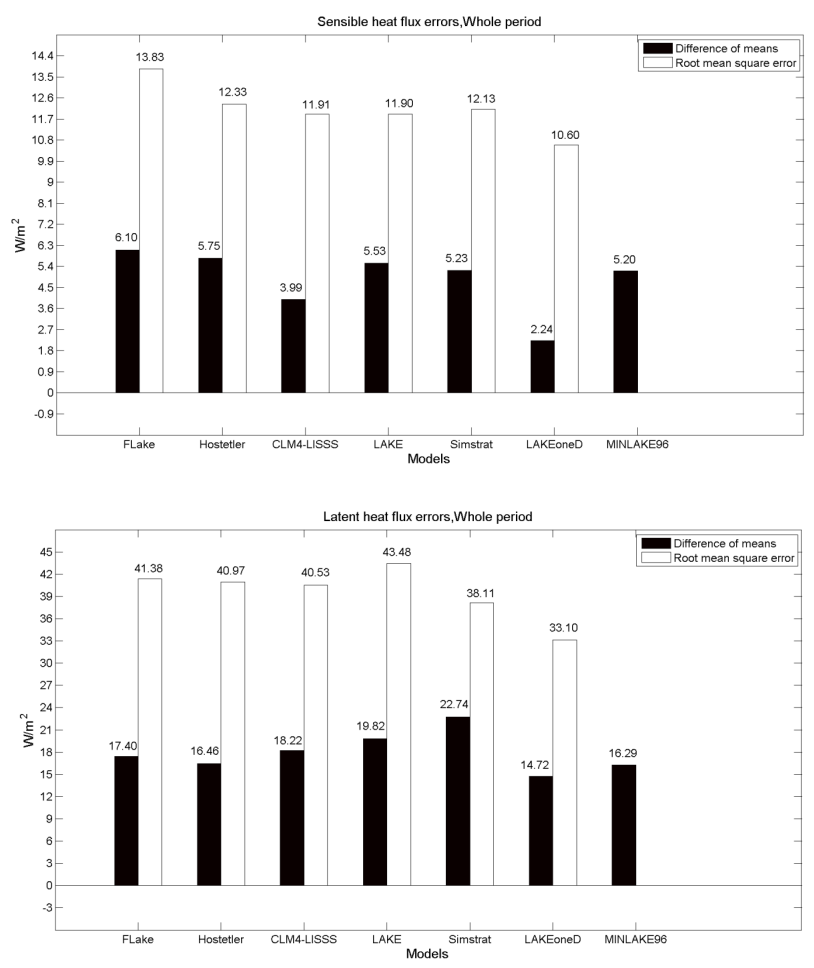

Fig. 7. Differences between modeled and observed means and models' RMSEs of sensible and latent heat flux. The mean measured sensible heat flux is $8 \mathrm{~W} \mathrm{~m}^{-2}$, and mean latent heat flux is $69 \mathrm{~W} \mathrm{~m}^{-2}$.

data flags, were involved (the effect of excluding data based on footprint criterion will be addressed below). The RMSEs are quite large, especially for sensible heat flux (10$14 \mathrm{~W} \mathrm{~m}^{-2}$ ), comparable to typical values of this flux that do not usually exceed several tens of $\mathrm{W} \mathrm{m}^{-2}$. Remarkably, all models have positive DMs and in most cases remain positive if calculated separately for summer and autumn (not shown). This may, to some extent, be caused by surface temperature biases, by peculiarities of surface turbulent flux schemes and by shortcomings of the eddy covariance measurement technique (see discussion of the latter issue below in this section).
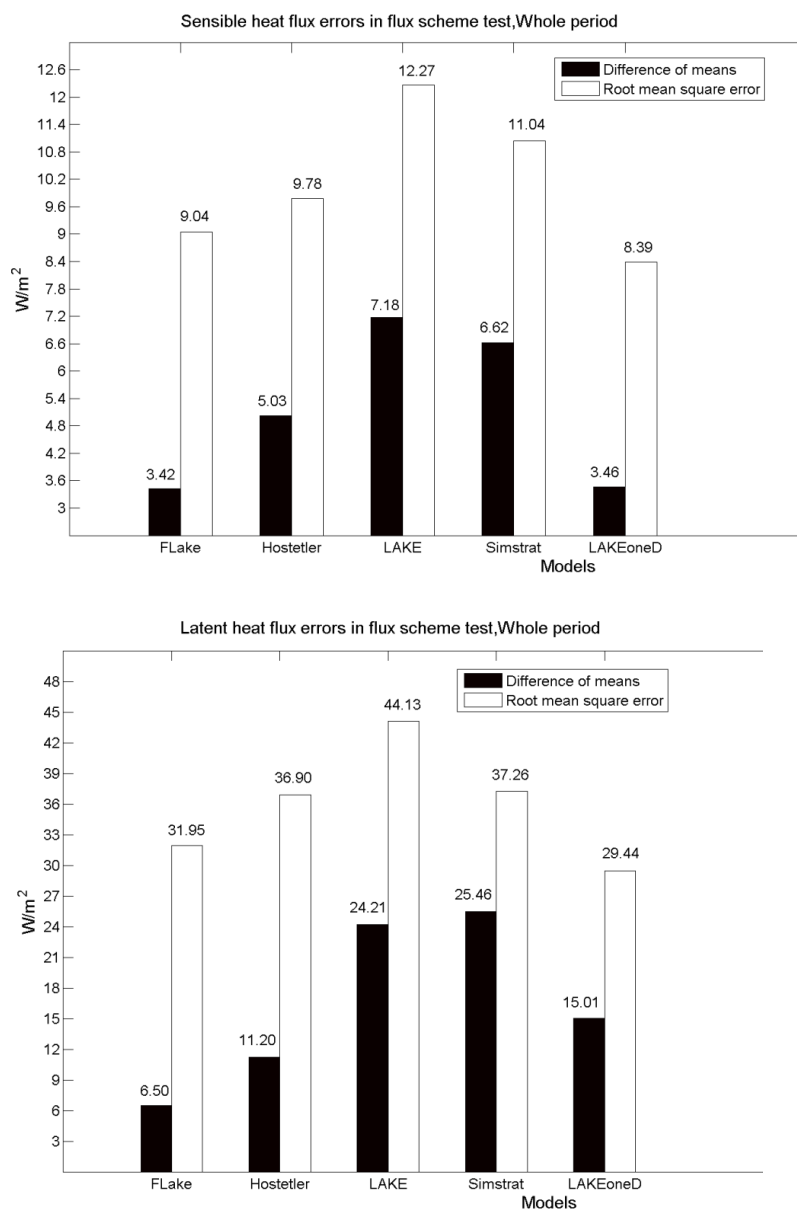

Fig. 8. Difference between computed and observed means and RMSEs of sensible and latent heat flux by stand-alone surface turbulent flux schemes. The mean measured sensible heat flux is $8 \mathrm{~W} \mathrm{~m}^{-2}$, and mean latent heat flux is $69 \mathrm{~W} \mathrm{~m}^{-2}$.

To exclude the impact of surface temperature model error and thus to test purely surface turbulent flux schemes, these schemes were detached from the rest of lake models, so that all input variables, including surface temperature, were 
taken from observations. The resulting error characteristics of schemes are shown in Fig. 8. It is clearly seen that both DMs and RMSEs of all models' schemes remained large. All DMs were again positive. Large RMSEs and systematic positive DMs could be caused by violation of horizontal homogeneity of atmospheric flow when it is directed from the nearest shores ( $90 \mathrm{~m}$ and more from the point of measurements). However, excluding all data with wind directions from the nearest shores indicated by a footprint analysis (directions from 60 to $200^{\circ}$ from the north) did not reduce substantially the deviations of surface flux scheme results from eddy covariance data.

Assessing the models' total surface heat flux errors, now we compare them to eddy covariance (EC) flux uncertainty. The latter was thoroughly analyzed for LITFASS-2003 experiment in Mauder et al. (2006) based on intercomparison of different EC measurement systems. It was demonstrated that RMSE ("RMSD" in that paper) of sensible and latent heat fluxes for the USA-1/LI-7500 system of Lindenberg Observatory used at Kossenblatter See, with respect to a reference one (CSAT3/LI-7500), were $15 \mathrm{~W} \mathrm{~m}^{-2}$ and $24.4 \mathrm{~W} \mathrm{~m}^{-2}$, respectively. These values are close to model error estimates (Figs. 7 and 8), thus preventing us from deriving any further definite conclusions on surface flux scheme quality based on comparison with eddy covariance data in terms of RMSE. Scrutinizing the possible reasons for positive DMs of model fluxes allows for more substantial analysis, presented below.

The systematic deviation of turbulent heat fluxes calculated by lake models and stand-alone flux schemes from those estimated by eddy covariance results in a corresponding difference of values of net energy flux into the lake (the net energy flux is defined here as the sum of net downwelling heat flux at the top of the water column and solar radiation penetrated through this surface). Net energy fluxes calculated by lake models and averaged over the entire integration period fell within a range of 6 to $13 \mathrm{~W} \mathrm{~m}^{-2}$, whereas this flux, calculated using observational data, was $26 \mathrm{~W} \mathrm{~m}^{-2}$. To assess if this additional heat input to the lake could be an important contribution for the lake's heat balance, an additional run of the LAKE model (for which the net energy flux to the lake in the reference run was $10 \mathrm{~W} \mathrm{~m}^{-2}$ ) was performed; this run was identical to the reference run, except that measured sensible and latent heat fluxes to the atmosphere were used instead of those calculated by surface flux scheme. In this simulation the modeled lake surface temperature was, on average, very high with the RMSE for the whole period being $3.83^{\circ} \mathrm{C}$ and DM $3.02^{\circ} \mathrm{C}$ (versus $0.99^{\circ} \mathrm{C}$ and $0.16^{\circ} \mathrm{C}$ in a reference run, respectively). This suggests that the measured turbulent heat fluxes do not allow for an observed onedimensional heat balance in the lake to be fulfilled, as the LAKE model has a conservative numerical scheme and was shown to reproduce correctly the stratification of Kossenblatter See in the reference run. To check this, the onedimensional heat balance of the lake using only measured data was calculated.
After integrating the three-dimensional advectiondiffusion temperature equation with a radiation source over the lake depth at a given point (location of measurements), we obtain

$\rho c_{p} h \frac{\mathrm{d} \bar{T}}{\mathrm{~d} t}=Q_{z=0}+F_{z=0}-Q_{z=h}-F_{z=h}+R$,

where $\bar{T}$ is the water temperature averaged over depth, $\rho$ water density, $c_{p}$ specific heat at constant pressure, $z$ the vertical coordinate pointing downwards, $h$ the lake depth, $Q$ the solar radiation penetrated in the water column, $F$ downward heat flux, and $R$ contains vertically integrated horizontal advection and diffusion terms. $Q_{z=h}$ is negligible due to the high lake turbidity, and $F_{h, z}=h$ was not measured at Kossenblatter See. The bottom heat flux $F_{h, z}=h$, calculated by the LAKE model, seemed to be small compared to other terms in Eq. (4). Taking this into account and substituting measured values to all terms of Eq. (4) except $R$, one obtains

$\rho c_{p} h \frac{\mathrm{d} \bar{T}^{*}}{\mathrm{~d} t}=Q_{z=0}^{*}+F_{h, z=0}^{*}+R+\delta$,

where asterisks denote observed values and residual $\delta$ arises from measurement inaccuracies, including inaccuracies of sensors and misrepresentation of real energy fluxes by measurement techniques (such as eddy covariance for turbulent fluxes). Note also that $\bar{T}^{*}$ derived from the integral of temperature over the lake depth cannot be directly measured, and instead is estimated using data from temperature sensors at the discrete depths that contribute to $\delta$ as well. From Eq. (5), the time series of $R+\delta$ was calculated for the whole period of measurements with temporal resolution of eddy covariance measurements $(30 \mathrm{~min})$, using temperature sensors data at depths 2,10,20,50 and $100 \mathrm{~cm}, h=1.2 \mathrm{~m}$, global solar radiation and surface heat flux from sensors located at the mast (Sect. 3).

The mean value of $R+\delta$ for the whole period was $-28 \mathrm{~W} \mathrm{~m}^{-2}$. The problem is whether this residual may be mostly attributed to $R$ or $\delta$. Our value of $R+\delta$ is consistent with the values of mean one-dimensional energy balance residual obtained for Lake Valkea-Kotinen in Finland and at other lakes (see Nordbo et al., 2011, and references therein). The authors of this paper discuss the sources of such residual and conclude that a known systematic underestimation of turbulent fluxes by eddy covariance technique, due to the missing contribution of large-scale turbulent eddies (secondary circulations) (Foken, 2008), is one of the most probable candidates (in our terms it means that $\delta$ is prevailing). The corresponding lack of low-frequency contribution to turbulent fluxes has been identified in a number of experimental and modeling (LES) studies, overviewed in Eddy Covariance (2012). The authors conclude inter alia that the spatial inhomogeneities with scales from $100 \mathrm{~m}$ to $\sim 10 \mathrm{~km}$ are most likely to cause secondary circulations whose effect is missing in eddy covariance measurements with $\sim 10 \mathrm{~min}$ averaging. 
The size of Kossenblatter See falls in this range. Another possible source for systematic underestimation of real fluxes by the EC technique is caused by sensor-specific errors (Mauder et al., 2006). It is shown by these authors that DM ("the bias" in that paper) of total heat flux for the USA-1/LI-7500 system used at the Lindenberg Observatory with respect to a reference device was $\approx-4 \mathrm{Wm}^{-2}$. The total heat fluxes for other devices taking part in this study deviated on average by 10 $30 \mathrm{~W} \mathrm{~m}^{-2}$ from the reference one. This range of uncertainty due exclusively to sensor design suggests that the heat imbalance in our study can be significantly affected by this factor as well.

Consider now the term $R$, whose contribution to total residual accounts for internal circulations in a lake (seiches, Langmuir circulations and others), and also the advection from inflow. Kossenblatter See has no major inlet so that an inflow may be caused only by brooks, underground discharge or diffuse inflow from the catchment. These effects can be roughly estimated in terms of heat advection as follows.

Consider the volumetric heat balance of a lake assuming the equality of total outlet and inlet discharges (it can be easily shown that given typical latent heat flux values the evaporation is $\sim 10 \%$ of runoff from the lake catchment and thus can be omitted):

$\rho c_{p} V \frac{\mathrm{d} \tilde{T}}{\mathrm{~d} t}=\ldots \rho c_{p} D\left(T_{\mathrm{in}}-T_{\text {out }}\right)+S\left(\hat{Q}_{z=0}+\hat{F}_{h, z=0}\right)$,

where $V$ is the lake volume, $D$ the total outlet discharge, $\tilde{T}$ the volumetric mean lake temperature, $T_{\text {in }}$ and $T_{\text {out }}$ the mean inlet and outlet water temperatures, respectively, and $S$ the lake surface area, with $(\hat{\ldots})$ denoting an average over the lake surface. Thus the surface energy flux increment $\delta \hat{F}_{h, z=0}$ equivalent to the advection term is given by

$\delta \hat{F}_{h, z=0}=\frac{\rho c_{p} D\left(T_{\text {in }}-T_{\text {out }}\right)}{S}$.

Inlet discharge can be estimated as $D=S_{\mathrm{b}} r$ with $S_{\mathrm{b}}$ being the lake catchment area and $r$ the atmospheric precipitation rate, respectively. Finally, in order to obtain an upper estimate for $\delta \hat{F}_{h, z=0}$, we set the temperature difference in Eq. (7) to $10^{\circ} \mathrm{C}$ (the sign is irrelevant since we assess a magnitude of the term). Now substituting typical precipitation rate for Berlin neighborhood as $500 \mathrm{~mm} \mathrm{yr}^{-1}$, Kossenblatter catchment area 2384 ha and the lake surface area 170 ha, we obtain $\delta \hat{F}_{h, z=0} \approx 9 \mathrm{Wm}^{-2}$. Thus, heat advection entering $R$ may at most cause one-third of $R+\delta$. However, this estimate is based on assumption $T_{\text {in }}-T_{\text {out }} \approx 10^{\circ} \mathrm{C}$, which may be valid for instant time moments but is unlikely to be representative for seasonal timescales. Indeed, it is natural to expect that $T_{\text {in }}$ is close to soil temperature, the top layers of which typically exhibit larger diurnal cycle amplitude than those of a lake, and the same holds for seasonal variability. Hence, the temperature difference considered is likely to change sign at diurnal and seasonal timescales so that the seasonal averag- ing of $\delta \hat{F}_{h, z=0}$ should reduce the above estimate. Unfortunately, more precise assessment of the advection term contribution to the lake heat budget is limited by uncertainty of $T_{\text {in }}$.

As to the second contributor to $R$ - internal circulations it is hardly possible to quantify their influence at a physically solid basis given the available observation data, but we tend to assume that these are unlikely able to provide systematic heat source at a given point when averaging over a seasonal timescale. Thorough testing of this approximation, however, would need the use of 3-D hydrodynamic lake model forced by known atmospheric time series, which we leave for future research.

As a conclusion for this discussion, we recall that the DMs of total turbulent heat flux produced by surface flux schemes range from 17 to $28 \mathrm{~W} \mathrm{~m}^{-2}$ (Fig. 8), and thus if eddy covariance measurements underestimated the net heat flux by $\sim 20-30 \mathrm{~W} \mathrm{~m}^{-2}$ (entering the term $\delta$ ), this would explain a large fraction of both the mean residual of the heat balance in Eq. (5) and DMs of flux schemes.

\section{Conclusions}

A one-dimensional lake model intercomparison study, using observation data collected at Großer Kossenblatter See (Germany) during the open-water season (1 May-10 November) of the year 2003, was performed. All models generally captured diurnal and seasonal variability of the lake surface temperatures satisfactorily, except for the "completely mixed" model, which substantially smoothed the diurnal cycle. FLake and Hostetler models failed to correctly reproduce lake stratification in summer, which is most likely caused by insufficient wind-driven turbulent mixing in these models. It was shown that neglecting heat interaction with bottom sediments leads to no significant systematic changes of lake surface temperature (which is of the order of temperature sensor resolution) during the May-August period. In August-October, the negative shift of the simulated mean temperature, when omitting sediments, is greater (up to $-0.4^{\circ} \mathrm{C}$ ), which is consistent with more intensive heat exchange with bottom sediments. In experiments with different lake depths (local depth in the point of measurements of $1.2 \mathrm{~m}$, mean lake depth of $2 \mathrm{~m}$, and maximal depth of $5 \mathrm{~m}$ were used), the best correspondence of calculated surface temperature with measurements was obtained for $1.2 \mathrm{~m}$ and $2 \mathrm{~m}$ depths, while using $5 \mathrm{~m}$ depth led to extra thermal inertia of the modeled lake. The discrepancy in bottom temperature between models (up to $10^{\circ} \mathrm{C}$ ) was much larger than that of surface temperature; a number of contributing factors, such as differences in vertical turbulent mixing parameterization, initialization of soil temperature profile, thickness of the soil layer considered in participating models, may be involved. The sensitivity of bottom temperature to neglecting sediments was also model-dependent. Sensible and latent heat 
fluxes provided by the lake models had a systematic positive DM with respect to values measured by the eddy covariance method. The total turbulent heat flux had a difference of means (DM) of $17-28 \mathrm{~W} \mathrm{~m}^{-2}$, depending on the model. Very similar values of total turbulent heat flux DM were obtained when surface turbulent flux schemes were forced only by observation data (including water surface temperature). The residuals of the one-dimensional heat balance of the lake assessed, based on measurements only and averaged over the whole simulation period, fell in the same range for all models. This suggests that the eddy covariance technique underestimated turbulent heat fluxes - a known peculiarity of this method, already reported in a number of earlier studies.

As an overall assessment of different lake models of this study, it is concluded that (i) turbulent mixing parameterization should be used even for such shallow, turbid, polymictic lakes as Kossenblatter See, instead of applying the simple complete-mixing approach in order to reproduce the surface temperature correctly; (ii) the presence of bottom sediment parameterization in a model does not much affect the course of surface temperature during the open-water period when the lake temperature rises (until the mid-August); the effect of sediments in autumn (August-October) is considerably stronger; (iii) the energy budget at the lake surface is a primary driver for the lake surface temperature, so that even larger errors of reproducing the bottom temperature and stratification still allow a quite realistic calculation of the mixed-layer temperature. This is especially important when using lake models in NWP or climate models without sufficient knowledge of the hydrogeology of lakes. However, it has to be pointed out that our experiments using different lake depths, based on its bathymetry, showed that using a "wrong" depth considerably different from the average one ( $5 \mathrm{~m}$ instead of 2 or $1.2 \mathrm{~m}$ ) could lead to a substantial bias in the surface temperature.

\section{Supplementary material related to this article is available online at: http://www.geosci-model-dev.net/6/ 1337/2013/gmd-6-1337-2013-supplement.pdf.}

Acknowledgements. Victor Stepanenko was supported by a grant from the Russian Foundation for Basic Research (RFBR) 12-0501068-a, by a grant from the Council of President of Russian Federation for support of young Russian scientists and leading research schools MK-6767.2012.5, and by a grant from the Russian Ministry for Education and Science No.2012-1.2.2-12-000-1008-0301.

Andrey Martynov was supported by Canadian Foundation for Climate and Atmospheric Sciences (CFCAS), the Ministère du Développement économique, Innovation et Exportation (MDEIE), the Ouranos Consortium on Regional Climatology and Adaptation to Climate Change, the Natural Sciences and Engineering Research Council of Canada (NSERC), and Mathematics of Information
Technology and Complex systems (MITACS). Authors are grateful to Annika Nordbo from University of Helsinki for useful discussions on interactions of small lakes with atmosphere in midlatitudes.

Edited by: M. T. Coe

\section{References}

Balsamo, G., Dutra, E., Stepanenko, V. M., Viterbo, P., Miranda, P. M. A., and Mironov D.: Deriving an effective lake depth from satellite lake surface temperature data: a feasibility study with MODIS data, Boreal Environ. Res., 15, 178-190, 2010.

Beljaars, A. C. M. and Holtslag, A. A. M.: On flux parameterization over land surfaces for atmospheric models, J. Appl. Meteorol., 30, 327-341, 1991.

Beyrich, F. and Mengelkamp, H. T.: Evaporation over a heterogeneous land surface: EVA_GRIPS and the LITFASS-2003 Experiment - an Overview, Bound.-Lay. Meteorol., 121, 5-32, 2006.

Beyrich, F., Leps, J. P., Mauder, M., Bange, J., Foken, T., Huneke, S., Lohse, H., Luedi, A., Meijninger, W. M. L., Mironov, D., Weisensee, U., and Zittel, P.: Area-averaged surface fluxes over the LITFASS region based on eddy-covariance measurements, Bound.-Lay. Meteorol., 121, 33-65, 2006.

Bonan, G. B.: Sensitivity of a GCM simulation to inclusion of inland water surfaces, J. Climate, 8, 2691-2704, 1995.

Dickinson, R. E., Henderson-Sellers, A., and Kennedy, P. J.: Biosphere-Atmosphere Transfer Scheme (BATS) Version 1e as coupled to the NCAR Community Climate Model, available from NCAR Education and Outreach Program, P.O. Box 3000, Boulder, CO, 80307, NCAR Tech. Note NCAR/TN-3871STR, 72 pp., 1993.

Dingman, S. L., Weeks, W. F., and Yen, Y. C.: The effects of thermal pollution on river ice conditions, Water Resour. Res., 4, 349-362, 1968.

Dutra, E., Stepanenko, V. M., Balsamo, G., Viterbo, P., Miranda, P. M. A., Mironov, D., and Schär, C.: An offline study of the impact of lakes on the performance of the ECMWF surface scheme, Boreal Environ. Res. 15, 100-112, 2010.

Eddy Covariance: A Practical Guide to Measurement and Data Analysis, Series: Springer Atmospheric Sciences, edited by: Aubinet, M., Vesala, T., and Papale, D., XXII, 438 pp., 2012.

Fairall, C. W., Bradley, E. F., Godfrey, J. S., Edson, J. B., Young, G. S., and Wick, G. A.: Cool skin and warm layer effects on sea surface temperature, J. Geophys. Res., 101, 1295-1308, 1996.

Fang, X. and Stefan, H. G.: Long-term lake water temperature and ice cover simulations/measurements, Cold Reg. Sci. Technol., 24, 289-304, 1996.

Foken, T.: The energy balance closure problem: an overview, Ecol. Appl., 18, 1351-1367, 2008.

Forbes, G. S. and Meritt, J. H.: Mesoscale vortices over the Great Lakes in wintertime, Mon. Weather Rev., 112, 377-381, 1984.

Goudsmit, G.-H., Burchard, H., Peeters, F., and Wüest, A.: Application of $\mathrm{k}-\varepsilon$ turbulence models to enclosed basins: The role of internal seiches, J. Geophys. Res., 107, 3230-3243, 2002.

Goyette, S., McFarlane, N. A., and Flato, G.: Application of the Canadian Regional Climate Model to the Laurentian Great Lakes Regions, Implementation of a Lake Model, Atmos. Ocean., 38, 481-503, 2000. 
Hostetler, S. and Bartlein, P.: Simulation of Lake Evaporation with Application to Modeling Lake Level Variations of HarneyMalheur Lake, Oregon, Water Resour. Res., 26, 2603-2612, 1990.

Hostetler, S. W., Bates, G. T., and Giorgi, F.: Interactive coupling of a lake thermal model with a regional climate model, J. Geophys. Res., 98, 5045-5057, 1993.

Jöhnk, K. D. and Umlauf, L.: Modelling the metalimnetic oxygen minimum in a medium sized alpine lake, Ecol. Model., 136, 6780, 2001.

Jöhnk, K. D., Huisman, J., Sommeijer, B., Sharples, J., Visser, P. M., and Stroom, J.: Summer heatwaves promote blooms of harmful cyanobacteria, Glob. Change Biol., 14, 495-512, 2008.

Kirillin, G., Hochschild, J., Mironov, D., Terzhevik, A., Golosov, S., and Nützmann, G.: FLake-Global: Online lake model with worldwide coverage, Environ. Model. Softw., 26, 683-684, 2011.

Kuhn, W.: Aus Wärmehaushalt und Klimadaten berechnete Verdunstung des Zürichsees, Vierteljahrschrift der naturforschenden Gesellschaft in Zürich, 123, 261-283, 1978.

Large, W. G., McWilliams, J. C., and Doney, S. C.: Oceanic vertical mixing: a review and a model with nonlocal boundary layer parameterization, Rev. Geophys., 32, 363-403, 1994.

Livingstone, D. M. and Imboden, D. M.: Annual heat balance and equilibrium temperature of Lake Aegeri, Switzerland, Aquat. Sci., 51, 351-369, 1989.

Long, Z., Perrie, W., Gyakum, J., Caya, D., and Laprise, R.: Northern lake impacts on local seasonal climate, J. Hydrometeorol., 8, 881-896, 2007.

Mauder, M., Liebethal, C., Göckede, M., Leps, J.-P., Beyrich, F., and Foken, T.: Processing and quality control of flux data during LITFASS-2003, Bound.-Lay. Meteorol., 121, 67-88, doi:10.1007/s10546-006-9094-0, 2006.

Mironov, D. V.: Parameterization of lakes in numerical weather prediction. Description of a lake model, COSMO Technical Report, No. 11, Deutscher Wetterdienst, Offenbach am Main, Germany, 41 pp., 2008.

Mironov, D., Heise, E., Kourzeneva, E., Ritter, B., Schneider, N., and Terzhevik, A.: Implementation of the lake parameterisation scheme FLake into the numerical weather prediction model COSMO, Boreal Environ. Res., 15, 218-230, 2010.

Nordbo, A., Launiainen, S., Mammarella, I., Leppäranta, M., Huotari, J., Ojala, A., and Vesala, T.: Long-term energy flux measurements and energy balance over a small boreal lake using eddy covariance technique, J. Geophys. Res., 116, D02119, doi:10.1029/2010JD014542, 2011.
Oleson, K. W., Lawrence, D. M., Bonan, G. B., Flanner, M. G., Kluzek, E., Lawrence, P. J., Levis, S., Swenson, S. C., Thornton, P. E., Dai, A., Decker, M., Dickinson, R., Feddema, J., Heald, C. L., Hoffman, F., Lamarque, J.-F., Mahowald, N., Niu, G.-Y., Qian, T., Randerson, J., Running, S., Sakaguchi, K., Slater, A., Stockli, R., Wang, A., Yang, Z.-L., Zeng, X., and Zeng, X.: Technical description of version 4.0 of the Community Land Model (CLM). National Center for Atmospheric Research, NCAR/TN478+STR, 257 pp., 2010.

Paulson, C. A.: The mathematical representation of wind speed and temperature profiles in the unstable atmospheric surface layer, J. Appl. Meteorol., 9, 857-861, 1970.

Perroud, M., Goyette, S., Martynov, A., Beniston, M., and Anneville, O.: Simulation of multiannual thermal profiles in deep Lake Geneva: A comparison of one-dimensional lake models, Limnol. Oceanogr., 54, 1574-1594, 2009.

Poole, H. H. and Atkins, W. R. G.: Photo-electric measurements of submarine illumination throughout the year, J. Mar. Biol. Assoc., 16, 297-324, 1929.

Rodi, W.: Turbulence Models and their Application in Hydraulics a State of the Art Review, 3rd Edn., Baalkema, Rotterdam, The Netherlands, 1993.

Stepanenko, V. M., Goyette, S., Martynov, A., Perroud, M., Fang, X., and Mironov, D.: First steps of a Lake Model Intercomparison Project: LakeMIP, Boreal Environ. Res., 15, 191-202, 2010.

Stepanenko, V. M., Machul'skaya, E. E., Glagolev, M. V., and Lykosov, V. N.: Numerical Modeling of Methane Emissions from Lakes in the Permafrost Zone, Izv. AN. Fiz. Atmos. Ok+., 47, 275-288, 2011.

Subin, Z. M., Riley, W. J., and Mironov, D.: An Improved Lake Model for Climate Simulations: Model Structure, Evaluation, and Sensitivity Analyses in CESM1, J. Adv. Mod. Earth Sys., 4, M02001, doi:10.1029/2011MS000072, 2012.

Tranvik, L. J., Downing, J. A., Cotner, J. B., Loiselle, S. A., Striegl, R. G., Ballatore, T. J., Dillon, P., Finlay, K., Fortino, K., Knoll, L. B., Kortelainen, P. L., Kutser, T., Larsen, S., Laurion, I., Leech, D. M., McCallister, S. L., McKnight, D. M., Melack, J. M., Overholt, E., Porter, J. A., Prairie, Y., Renwick, W. H., Roland, F., Sherman, B. S., Schindler, D. W., Sobek, S., Tremblay, A., Vanni, M. J., Verschoor, A. M., von Wachenfeldt, E., and Weyhenmeyer, G. A.: Lakes and reservoirs as regulators of carbon cycling and climate, Limnol. Oceanogr., 54, 2298-2314, 2009.

$\mathrm{Wu}, \mathrm{J} .:$ Wind stress and surface roughness at air-sea interface, J. Geophys. Res., 74, 444-455, 1969. 